\title{
ESCRITURAS EN LA COMPAÑÍA DE JESÚS, EL LIBRO DE CONSULTAS DE PROVINCIA Y LAS HISTORIAS DE PROVINCIA
}

\author{
Writings in the Society of Jesus, "libro de consultas de provincia" and \\ "historias de provincia"
}

\author{
Josefina Cargnel* \\ https://orcid.org/0000-0003-3016-9627
}

\section{Resumen}

La escritura cumplió un papel muy importante dentro de la Compañía de Jesús, en la cual tomar registro de las cosas se convirtió en una necesidad de gobierno; para esto desarrolló un estricto círculo de correspondencia y de informes para fomentar y mantener la unión de la Orden. Al mismo tiempo promovía la escritura "para mostrar" a través de libros e Historias que daban cuenta del accionar de los jesuitas en el mundo conocido. Nos proponemos realizar un análisis comparativo entre el "Libro de consultas de provincia" y las Historias de Provincia escritas por Pedro Lozano en la primera mitad del siglo XVIII. Centramos nuestro análisis en la escritura y en la forma discursiva de cada uno, buscando observar el "Libro de consultas" como una mirada más cotidiana de los sucesos vividos en la Provincia que aquella fijada en las historias oficiales para acercarnos a la escritura jesuítica como un producto de "alguien" - historiador, secretario, consultor condicionado por su lugar y su contexto, más allá del mensaje que transmite esa escritura.

$<$ Escritura $><$ Compañía de Jesús $><$ Formas discursivas $><$ Provincia del Paraguay $>$

\begin{abstract}
Writing played an important role in the Society of Jesus, and recording became a need for the government. A strict circle of correspondence and reports to keep the union of the Order was developed. At the same time, the government promoted writing through books to show the jesuits' activities in the known world. In this paper, we comparatively analyze the Libro de consultas de provincia and the Historias de Provincia written by Pedro Lozano in the 18th century. We focus our analysis on the writing and the discursive form of each text to observe the Libro de consultas de provincia as a more daily look of the events of the province than the one from the official histories. We approach Jesuitic writings as the expressions of someone's product (a historian, a secretary, a consultant) conditioned by its place and context beyond the message transmitted.
\end{abstract}

$<$ Writing $><$ Society of Jesus $><$ Discursive forms $><$ Paraguay Province $>$

Recibido: 11/08/2020//Aceptado: 26/10/2020

* Departamento de Ciencias de la Información y Departamento de Historia, Facultad de Humanidades, Universidad Nacional del Nordeste (UNNE), Resistencia, Argentina, jgcarnel@gmail.com 
Cargnel. Escrituras en la Compañía de Jesús, el libro de consultas de provincia y las historias de provincia.

\section{Los jesuitas y la escritura}

A partir del siglo XIV con la invención de la imprenta, la lectura y la escritura "se" transforman y "transforman" el mundo de la época; la ampliación del acceso a los libros debido a la imprenta generó una explosión que transformó dichas prácticas, tanto en latín como en lenguas vernáculas. En ese contexto, se forma una Orden Religiosa nueva - la Compañía de Jesús - orientada a la misión y a la defensa de la Fe católica, sumando a los votos habituales el $4^{\circ}$ voto de "de obediencia al Sumo Pontífice". En ella la escritura cumplió un papel muy importante, en la cual tomar registro de las cosas se convirtió en una necesidad para dar cuenta de las actividades que realizaba la nueva institución.

Desde la constitución de la Orden sus miembros se diseminaron por el mundo conocido para expandir la religión, por esto su fundador y primer Padre General, Ignacio de Loyola, insistía en la necesidad de comunicarse a través de las cartas, convirtiendo a la escritura en un elemento central de gobierno. Así, la Compañía creó un estricto círculo de correspondencia y de informes que se movían dentro de la misma, estableciendo la frecuencia y los aspectos que debían informarse, para fomentar y mantener la unión de una orden religiosa nueva, que crecía rápidamente.

Debido al espacio que la Compañía iba ocupando en los reinos europeos, esta promovió, en paralelo a la escritura de gobierno, la redacción de historias que se alentaron desde la sede central en Roma, para registrar la vida y los hechos realizados por los primeros jesuitas. Después de la muerte de Ignacio y sus primeros compañeros, fue necesario escribir las biografías de aquellos padres fundadores. Estas biografías, escritas por Juan de Polanco, combinaban los sucesos de la vida de los biografiados, con los orígenes de la propia Compañía, por lo que se convirtieron en fundantes y modelos tanto para las historias como para las biografías que les siguieron.

Con la llegada de Claudio Acquaviva al cargo máximo de la Orden, la escritura de historias se convirtió en un proyecto a escala universal (Alcantara Bojorge, 2009), ya que este envió instrucciones para que en todas las provincias se escribieron historias, con formatos similares, que debían narrar las tareas que la Orden realizaba en las zonas en las que actuaba. Por esto, la escritura fue uno de los elementos que nucleó a los jesuitas y que permitió difundir las noticias de las tareas que desempeñaban los misioneros en las nuevas regiones descubiertas.

Esta cantidad de escritos que circulaban, desde y hacia la sede generalicia, así como los libros destinados a editarse, fueron definiendo dos "modos" de escritura que pueden aplicarse a toda la producción de la Antigua Compañía": una "escritura para mostrar" y otra escritura "no mostrable" (Morales, 2005). La primera es la que podemos definir como "apologética y propagandística" cuyos fines eran claros y se concentraban en la exposición de las tareas de la Compañía y su utilidad para la Iglesia y los reinos cristianos, como las Historias, Relaciones, etc. La segunda, en cambio, incluye la documentación de índole interna que respondía específicamente al gobierno

\footnotetext{
${ }^{1}$ En 1773 la Compañía fue Suprimida por el Papa Clemente XIV y restaurada en 1814 por Pio VII, llamamos "Antigua Compañía" al primer periodo desde la fundación hasta la Supresión y "Nueva Compañía" desde la Restauración hasta la actualidad.
} 
de la Compañía, como los memoriales, libros de consultas, libro de órdenes, etc. A través de este tipo de escritura la sede generalicia se enteraba de los sucesos e impartía instrucciones, órdenes, designaciones y castigos.

Numerosos autores han estudiado y clasificado los distintos géneros de escritura jesuítica, y son posibles innumerables clasificaciones dependiendo los criterios que se establezcan para ello ${ }^{2}$. Entre dichos géneros podemos mencionar las historias generales del accionar de la Compañía en el mundo, las que referían los sucesos de una casa, un colegio o una provincia; las obras del exilio, las cartas annuas, hasta una gran cantidad de documentos de tipo administrativo como papeles, billetes, cartas, informes y relaciones de viaje que circulaban desde y hacia Roma y entre las provincias. Consideramos que las historias jesuíticas pueden pensarse como una historia de la praxis, ya que prevalece en las obras el tono utilitario que perseguía fortalecer la identidad y la utilidad de la Orden en los espacios en los que se desempeñaba. Estos escritos, utilizando la amplificatio, que remarcaba numerosas veces las mismas figuras, perseguían construir "ejemplos" de escritura, de misionero, de superior, entre otras formas que remarcaban los parámetros para ser "un buen jesuita".

Para analizar la historiografía jesuítica es bueno tener presente que estos textos formaban parte de un sistema retórico propio de la institución, y que todas las acciones de los jesuitas estaban regidas por el trabajo de discernimiento desde su formación. Por esto, si bien tienen características propias, consideramos que dichas narraciones constituyen una mediación de la realidad observada por estos religiosos; ya que entendemos que en la escritura, como lo señala Chartier (2001), no hay una frontera rígida entre la realidad y el discurso que se asienta sobre ella. Así, entendemos que los discursos jesuíticos se construyen y re-construyen con la circulación de textos, ya que hay una realidad que se fijaba con un escrito, pero era revisada y re-construida con las nuevas noticias, espacios y costumbres que ampliaban el mundo conocido.

Sin duda, al reflexionar sobre la escritura, es necesario tener presente que cada sujeto que escribe está condicionado por su lugar, sus tareas, su puesto dentro de la institución, es decir, su contexto en sentido amplio. Si estos condicionantes son válidos para nuestro trabajo, teniendo una carga teórica que permite objetivarlos, no debemos perder de vista en la lectura de textos del siglo XVIII, como los que trabajamos, los condicionantes del contexto de aquellos sujetos. En este sentido, son útiles las ideas de "escritura afectada" para comprender el choque que generó en los europeos el contacto con el indígena y como este marcó la escritura, ya que "la afectación es una cualidad construida a través del encuentro traumático y de la capacidad de resiliencia del sujeto, poniendo en evidencia al menos dos maneras de concebir la ordenación y el funcionamiento del mundo: el de quien se afecta y el del afectado" (Galhegos Felippe y Paz, 2019, p. 201).

\footnotetext{
2 Son innumerables los autores que han trabajado este tema, solo a modo de ejemplo realizando un recorte arbitrario podemos mencionar a Guillermo Furlong (1994), Efraín Cardozo (1953), Francisco Esteve Barba (1964), Rómulo Carbia (1940), Ernesto Maeder (2018).
} 
Cargnel. Escrituras en la Compañía de Jesús, el libro de consultas de provincia y las historias de provincia.

Partiendo de estas nociones de escritura, nos proponemos analizar de forma comparativa dos géneros de escritura: el Libro de consultas de la provincia ${ }^{3}$, como escritura no mostrable, junto a las historias escritas por Pedro Lozano para la provincia del Paraguay en la primera mitad del siglo XVIII, como ejemplo, a su vez, de las escrituras mostrables. Buscamos centrar nuestro análisis en la escritura y en la forma discursiva que registran, partiendo de nuestro trabajo sobre las historias oficiales (Cargnel, 2015). Nos interesa acercarnos a la forma en que se articulaban ambos géneros en la vida cotidiana de los misioneros, ya que el Libro de consultas era una escritura "privada" destinada a un estamento de Superiores que debían velar por el buen gobierno y ejercicio de la tarea apostólica. Mientras los libros, por su parte, se destinaban a los refectorios y al público europeo ávido de conocer la realidad de los nuevos territorios.

Este interés surge a partir de nuestros estudios doctorales en los cuales buscamos analizar la escritura jesuítica, especialmente el caso de Pedro Lozano ${ }^{4}$, centrando la observación en sus obras históricas escritas entre 1730 y 1750, como un discurso que dicho jesuita fija del pasado y que se convierte en el registro oficial del mismo. Entendemos que la escritura sobre el pasado está condicionada por la mirada del presente que el sujeto, "historiador" en este caso, realiza sobre los hechos narrados. En este sentido el "libro de consultas", registrando distintos hechos en el mismo periodo, nos brinda observaciones más cotidianas de aquel presente de Pedro Lozano.

Para poder analizar la escritura, es necesario comprender el papel que la institución le asignó a la misma desde sus orígenes. Ignacio de Loyola había encargado a todos los jesuitas, en sus primeras cartas, que mantuvieran correspondencia frecuente informando las tareas que realizaban y la descripción de los lugares donde estaban, tanto donde eran bienvenidos como en las zonas en las que se los cuestionaba. Estos primeros informes delinearon la estructura que tendrían posteriormente las historias escritas por los jesuitas, especialmente a partir de las cartas del primer Secretario, Juan de Polanco, quien formalizó como escribir dichas cartas remarcando que en las letras mostrables se debía escribir sobre las residencias, cuantos padres eran, de qué se ocupaban, dónde y cómo vivían, las vecindades y los gentiles y en hijuelas la información más sensible. Es decir que, a través de las primeras cartas - y luego establecidas en las Reglas de la Compañía de Jesús - se regulaba minuciosamente no sólo la vida de los jesuitas, sino también qué y cómo se debía escribir.

Esta escritura se inscribe en la noción de Martín Morales de "mostrar y encubrir" (Morales, 2005, p. 45), la que remarca que todos los misioneros, especialmente los cronistas, tenían definido claramente lo que estaba permitido decir, lo que se podía "mostrar" y era edificante para la Compañía y lo que se debía "ocultar" — como las disidencias internas y los conflictos- regulación que está presente en toda la producción de la Compañía. Este análisis se funda en las ideas de Niklas Luhman (2006) sobre los grados de observaciones,

3 Este libro, como se explicará más adelante, debía registrar las consultas que realizaba el Provincial con su grupo de consultores.

${ }^{4}$ Nos referimos a Historia de la conquista, Descripción del Chaco, Historia de las revoluciones del Paraguay e Historia de la Compañia de Jesús en el Paraguay. 
por esto creemos que nuestra lectura es una observación de segundo grado sobre una realidad observada por el jesuita escribiente - ya fuera el cronista o el secretario- con sus propios condicionantes, que se fijan en diferentes formas discursivas, ya sean historias oficiales o documentos administrativos en este caso.

Por esto, mientras las historias de Lozano reflejan "una" observación del pasado que se establecía a través de la forma "historia" que es comprensible para nosotros y probablemente fuera fácilmente identificable por sus contemporáneos, el Libro de consultas fija las observaciones de un sujeto - aquel que registra las discusiones de la consulta- en otra forma discursiva:

"Para que se haga concepto de los colmados frutos que puede lograr el Evangelio en la conversión de tanto gentío [...] a ruego de personas celosas he formado esta Descripción de las provincias del Chaco, valiéndome de las noticias antiguas y modernas que se han podido recoger hasta ahora y estaban olvidadas en los archivos."

"En 3 de Febrero fueron las ultimas juntas en el Pueblo de Santa Rosa, en que fuera de lo tratado en las otras, resolvio su $\mathrm{R}^{\mathrm{a}}$ el Padre Provincial que los 4 Pueblos pagassen el sinodo al Padre Superior en plata en alguno de los oficios, como lo hazen los demas Pueblos; pues dicho Sinodo lo paga el Rey en plata, y no en lienzo"6.

Análisis como el que proponemos son necesarios para generar nuevos acercamientos al pasado de nuestros territorios, ya que la cantidad de escritura producida por la Orden - y la variedad de géneros - es una fuente fundamental para reconstruir el pasado colonial americano, ya que se consideraba que en estas podía hallarse información de todo tipo referida a los siglos XVI, XVII y XVIII. Durante el siglo XIX $\mathrm{y}$ principios del XX, en el marco de la formación de los estados nacionales, regidos por el historicismo clásico y la primacía del documento, los historiadores americanos utilizaron, para reconstruir dicho pasado, la escritura "mostrable", es decir libros y cartas anuas principalmente, como fuentes de primera mano considerando que - por su cercanía a los sucesos- permitían una reconstrucción verídica de los hechos del pasado. Al mismo tiempo, las historias que se escribieron durante esos siglos sobre la actuación de la Orden en estos territorios, generaron la construcción historiográfica de una imagen de la misma, todavía vigente, como un cuerpo unido, compacto y obediente a las decisiones que se tomaban en Roma, diferente a otras órdenes religiosas.

Las renovaciones historiográficas del siglo $\mathrm{XX}^{7}$ introdujeron nuevas reflexiones sobre los conceptos históricos y promovieron una ampliación en el uso de los documentos.

5 Lozano, 1941, p. 15.

6 Archivo General de la Nación, Sala VII, FBN, Legajo Nº 62, Libro de Consultas, f. 2.

7 Con renovación historiográfica nos referimos al movimiento de los años '30, donde cobran fuerza la Escuela de Annales, la Cliometría y el Marxismo Británico. A los que se sumaron posteriormente las 
Cargnel. Escrituras en la Compañía de Jesús, el libro de consultas de provincia y las historias de provincia.

Esto permitió comprender, a partir de allí, que la escritura "mostrable" plasmaba una realidad que no podía entenderse como la única verdad. Esto motivó la necesidad de utilizar documentos de carácter privado, ya que aquellos que fueran escritos en la cotidianeidad, y sin interés de historizar los sucesos, permitían una reconstrucción más cercana y acabada de los sucesos del pasado. Por otra parte, al acercarse al siglo XXI nuevas renovaciones historiográficas, influenciadas especialmente por el psicoanálisis y por las consecuencias del giro lingüístico, volvieron a replantear los estudios históricos afirmando que no hay un registro que pueda acercarnos directamente al pasado, sino que podemos acercarnos a las observaciones que los sujetos realizaban y que se fijan en distintas formas discursivas. En ese marco surgen nuevas conceptualizaciones, dentro de la historiografía jesuítica, que nos permiten el abordaje que proponemos desde el binomio escritura mostrable escritura no mostrable. Distanciándolos, a su vez, de conceptos de verdad y falsedad y abordándolos desde la concepción de la escritura afectada.

\section{Las "Historias" y el "Libro de consultas" nuestros corpus de análisis}

Nuestro trabajo está centrado en dos cuerpos documentales: las historias escritas por Pedro Lozano (1697 - 1752), quien fue designado desde 1730 y hasta su muerte Historiograpus provinciae, de acuerdo a los catálogos públicos de la provincia ${ }^{8}$. Este nombramiento lo convertía en el historiador oficial de la provincia, es decir que tenía libre acceso a los archivos para narrar las tareas realizadas por los jesuitas y que no se restringían a lo misional. Lozano, en este periodo, realizó cuatro obras históricas muy conocidas La Descripción Chorográfica del Gran Chaco (1733) y La historia de la Compañía (1754), que fueron editadas durante el siglo XVIII. A éstas se suman La historia de la conquista (1875) y La historia de las revoluciones del Paraguay (1905), que quedaron inéditas pero fueron publicadas durante los siglos XIX y XX. A las mismas se agregaban numerosas cartas e informes, entre ellas podemos mencionar las cartas annuas, atribuidas a su autoría, de los años 1720-1730, 1730-1735 y 17351743 (Salinas, 2017) y la Carta sobre el estado de situación de las fronteras en 1746, dirigida al Procurador Bruno Morales, o el Manuscrito de Observaciones al Manifiesto de Machuca Vargas (1959) en relación al Tratado de Límites firmado entre las Coronas Ibéricas. A los documentos administrativos, se suman también las traducciones de escritos históricos o de índole espiritual, que Lozano realizó hasta su muerte9?

Del abundante corpus mencionado, en este trabajo utilizaremos sus cuatro obras históricas que relatan, además del accionar de los jesuitas, una gran cantidad de detalles sobre los pueblos indígenas de la región, sucesos políticos, los procesos de descubrimiento y fundaciones de ciudades. Los cuales se convirtieron en fundantes de la historiografía rioplatense, destacando la calidad de los escritos de Lozano. Si bien pensamos a las cuatro como un cuerpo, en tanto un tipo de registro del pasado

renovaciones de la Escuela de Annales y las historias sectoriales.

8 Archivum Romanun Societatis Iesu (en adelante ARSI), Fondo Paraquaria (Catálogus Publicus

Provinciae Paraquaria.) 6, folio 168v.

9 El listado más completo hasta el momento puede consultarse en Furlong (1959): 
que respondía a objetivos $\operatorname{concretos}^{10}$, utilizaremos en mayor medida la Historia de las Revoluciones del Paraguay, ya que esta obra se convirtió en la voz oficial de una etapa vivida en primera persona por el autor. Los "sucesos" refieren al conflicto con los comuneros de Asunción, que ocurrieron en dicha ciudad entre 1720 y 1735 durante el cual los jesuitas vivieron la expulsión y restitución de su Colegio de Asunción, así como la derrota de sus milicias, entre otros acontecimientos. Escrita en 1735, este libro se presenta como la construcción de una realidad, y la fijación a través de una "Historia" de un suceso problemático. Su título remarca la necesidad de reseñar los sucesos históricos, aunque encarna la defensa de la actuación de los misioneros jesuitas y de los indígenas reducidos. Así "lo que pasó" se hacía presente por la observación que realizaba Lozano, por sí mismo o a través de sus compañeros, buscando "limpiar" el nombre de la Orden —como lo menciona en el prólogo- constituyéndose en voz de ese nosotros.

El manuscrito original de Lozano es un solo texto, aunque en la edición de 1905 se fragmentó en dos tomos: el primero titulado "Antequera" y el segundo "Los comuneros". El primer tomo aborda el conflicto desde el gobierno de Diego de los Reyes, la llegada de Antequera y su investigación en Asunción, los conflictos entre vecinos, la expulsión de los jesuitas, la batalla del Tebicuary, la llegada de Bruno Mauricio de Zabala y, finalmente, el apresamiento de Antequera y su muerte en Lima. El segundo tomo presenta las alteraciones de la provincia con la llegada del nuevo gobernador, los conflictos que se suscitaron nuevamente entre los partidos, la nueva expulsión de los jesuitas de su Colegio, la elección del obispo como gobernador, la segunda campaña de Bruno Mauricio de Zabala y la paz en la Provincia. Si bien esta obra se enmarca dentro de las Historias, y posee las características que señalamos para este género, constituye la fijación de una memoria institucional que pretendía presentar a la Compañía como una víctima del conflicto al detallar, por ejemplo, la expulsión del Colegio como parte de las afrentas que sufrieron afirmando que "la pluma entra con recelo, porque la mano trémula con el susto apenas la puede gobernar" (Lozano, 1905, p. 408). Estos comentarios remarcan la consideración del oficio de Lozano como historiador, y al mismo tiempo, nos permiten observar algunos de sus condicionantes al momento de fijar su observación.

El otro cuerpo documental con el que trabajamos es el Libro de Consultas que se encuentra en el Archivo General de la Nación de Argentina ${ }^{11}$, en el Fondo "Biblioteca Nacional"2". Este "Libro" fue citado en muchos trabajos, sin recibir un análisis particular, sino como una fuente de información que pudiera acercarnos a diversos hechos del pasado, tales como la presencia de esclavos en estancias jesuíticas, las construcciones que se realizaban, las cuestiones de tipo económicas —como el

\footnotetext{
${ }^{10}$ Para mayor información sobre las temáticas desarrolladas en cada una de las obras de Lozano confrontar Cargnel (2017).

${ }^{11}$ En adelante AGN.

${ }^{12}$ El Fondo Biblioteca Nacional reúne, por respeto a los principios archivísticos de orden natural de los documentos, los documentos que obraban en dicha biblioteca hasta el año 1954 y que después de la Creación del Archivo General de la Nación, con la promulgación del decreto 19021/54 de concentración de fondos documentales fueron transferidos y convertidos en parte de su acervo. En adelante FBN.
} 
Cargnel. Escrituras en la Compañía de Jesús, el libro de consultas de provincia y las historias de provincia.

precio de los géneros o los intercambios entre los colegios- pero sin preocuparse por la forma discursiva en que se registraban estas cuestiones y en la cual queremos concentrarnos. Sin duda, esta forma era reconocible para el "nosotros" jesuítico, ya que estaba señalada en la instrucción como debía registrarse la consulta, lo que ayudaría a reconocerlo como un "libro de consultas" y no otra cosa, pero de difícil abordaje para los "otros". En cuanto a la materialidad del mismo, debemos señalar que creemos que estaba formado por cuadernillos sueltos — que posiblemente fueran cosidos y encuadernados posteriormente- con tapas de pergamino por las marcas de pequeños agujeros simétricos que presenta. Fue intervenido con fines de restauración en el siglo XX y actualmente se presenta con los folios unidos entre sí, como consecuencia del proceso de restauración. Contiene 172 folios, numerados en forma continua, escritos en ambas caras, donde se asientan las consultas que realizaba el provincial reunido con sus consultores desde junio de 1731 a diciembre de 1747. A esto debemos sumarle dos folios, al final del cuaderno, que registran una consulta de 1740, con la esquina superior derecha cortada, que nos impide saber la numeración que hubiera tenido. Pero abona, no obstante, nuestra hipótesis de que pudieran haber sido cuadernillos sueltos que se cosían posteriormente.

Indudablemente, por la información que contiene, la obra mencionada estaría entre los documentos más reservados que tenía el Provincial a su disposición para tomar decisiones durante su gobierno. Si bien la realización del libro de consultas estaba consignada entre las tareas del socio provincial ${ }^{13}$, desconocemos si existieron otros libros de este tipo en la provincia, y de qué manera éste se conserva hasta llegar al acervo de la Biblioteca Nacional y de allí al AGN. Todo lo cual permite la generación de dudas sobre la originalidad del documento. Sin embargo, podemos afirmar que es una escritura característica del siglo XVIII, por el tipo de cursiva utilizada, aunque no podemos determinar si se tratan de las notas que se tomaban durante la consulta $-\mathrm{y}$ después se formalizaba la escritura- o si es un documento copiado posteriormente.

La primera página del "Libro" es una hoja guarda, que contiene unas letras y números, que posiblemente correspondieran al lugar donde estaba guardado el mismo, aunque no podemos saber si esa ubicación corresponde al periodo de la Biblioteca Nacional o a otros anteriores. A continuación, hay una copia de una carta del General Juan Pablo Oliva de 1680, que indica la necesidad de llevar este registro debido al aumento de la conflictividad que existía y a la necesidad del registro para facilitar la toma de decisiones. Esta carta fue publicada en 1911, junto a una serie de cartas de Padres Generales, en el marco de la publicación de las Monumenta Histórica Societatis Iesu, lo que nos plantea otra serie de cuestionamientos sobre la necesidad en el siglo XX de publicar reglamentaciones de siglos anteriores, como elementos para la escritura de una nueva historia de la Compañía. La posibilidad de confrontar la carta completa, publicada

\footnotetext{
${ }^{13}$ El socio provincial, si bien estaba subordinado al Provincial en la práctica, era un compañero que colaboraba con las tareas de gobierno de la provincia jesuítica. Quedan pendientes para nuevas reflexiones las tareas de cada miembro de la jerarquía del gobierno provincial de la Orden, ya que aparenta una jerarquía de tipo militar, aunque en el reflejo documental podemos inferir un entramado mucho más complejo que un mero verticalismo.
} 
con el extracto copiado en el "Libro", nos permitió observar numerosos errores en la copia, lo que aumenta la posibilidad de que fuera transcripto posteriormente, aunque no podemos inferir por el momento las razones o la necesidad de realizar una reproducción de este libro.

Por las indicaciones que brinda la carta, podemos suponer que existían otros libros de consultas, desde 1680 a 1731, y de 1747 en adelante. A lo que podemos agregar una referencia, en el mismo acto de la consulta, a otra realizada previamente y apuntada en otro libro - o en folios - que no se hallan presentes en la pieza analizada, al señalar: "que no obstante lo determinado en una Consulta de Provincia el año 730"14, lo que nos inclina a pensar que existía algún tipo de registro de las consultas que se realizaban y que el Provincial los tenía disponibles para su estudio. Del mismo modo, debemos suponer que todas las provincias deberían haber llevado sus libros de consultas, a indicación del General, pero desconocemos si pueden hallarse en los archivos.

El acto de la consulta, según el Instituto Societatis Iesu, se formaba con tres consultores, entre ellos "socii provincialis". A estos podían sumarse, para tratar temas específicos, los expertos que podrían incluir un especialista en moral, el procurador, el rector de una casa, entre otros consultores extraordinarios ${ }^{15}$. Las primeras reglas de consultores que se conservan son las de Coímbra (1545-1546), que fueron ampliadas en los generalatos de Francisco de Borja, Everardo Mercuriano y en el de Claudio Aquaviva y entre los deberes de los consultores, según el Diccionario Histórico de la Compañía de Jesús, retomados del Instituto, constan:

"la fidelidad a su cometido sin asumir parte alguna en el gobierno [...] la libertad de espíritu al expresar su opinión con sinceridad y modestia; la obediencia de juicio a la decisión final del superior; la capacidad para guardar secretos; el respeto por la persona del superior; y la escritura de relaciones ex oficio al general" (O’Neill y Domínguez, 2001, p. 935).

El "Libro" también nos ofrece información sobre la participación de estos consultores, ya que estando en Córdoba el provincial, parecería que se reúne con sus consultores ordinarios, pero realizando la visita de los otros colegios, estancias o pueblos. Este cuerpo consultivo se formaba con quienes estuvieran a disposición y reunieran las condiciones necesarias para realizarlo. Por esto, quizás, se necesitaba señalar cuáles eran las reglas con las que los consultores debían manejarse, dejando constancia de los pasos que se daban para iniciar la consulta, leyendo primero las reglas de los consultores y del admonitor y después comenzando la consulta propiamente dicha: "a siete de junio se empezó la consulta en este colegio [de la Rioja] y en los días siguientes se leyó lo que se acostumbra y se tuvieron las consultas de lo temporal y de lo espiritual"16. En la situación de las visitas, que el provincial debía realizar, nuevamente se plantea la cuestión

\footnotetext{
${ }^{14}$ AGN. Sala VII. FBN Nº62. LdC, f 014.

${ }^{15}$ Instituto Societatis Iesu, 1893, pp. 137-138.

${ }^{16}$ AGN, Sala VII, FBN No 62, LdC f. 54.
} 
Cargnel. Escrituras en la Compañía de Jesús, el libro de consultas de provincia y las historias de provincia.

de las manos que registran la consulta, ya que desconocemos si el socio del provincial viajaba junto a este y, por lo tanto, participa de las consultas o no, debido a que en algunas consultas aparece como consultor el "Padre Secretario", pero esto no es constante.

En cuanto a las características del historiador, Acquaviva señalaba en las Instrucciones las condiciones que debían reunir los historiadores, indicando que el Provincial debía encontrar a la persona acertada que pudiera encargarse de esta tarea, brindándole el acceso a los "papeles" para que remitiesen a Europa las noticias que nutrirían las historias de la Compañía. Asimismo, se señalaba que pudieran disponer del tiempo que necesitaban, entendiendo que era una tarea ardua: "por la magnitud de la empresa y el cuidado que exige un asunto de tal importancia, ha sido difícil encontrar una persona a la cual fuera impuesto este trabajo" (Alcantara Bojorge, 2009, p. 68). Esta expresión nos permite entender la exclusividad de la tarea del historiador, que los autores que estudiaron la figura de Lozano a principios de siglo no pudieron comprender, considerando paradigmático que estuviera dedicado específicamente a las tareas historiográficas. En este sentido es necesario remarcar, por las características del historiador, que no podía coincidir su tarea con la de ser socio del provincial. Esto puede confirmarse en los catálogos de provincia, ya que si bien se registran otras ocupaciones, la tarea principal que se le asigna a Lozano es la de historiador provincial. Es decir que, para nuestro análisis, tenemos a dos sujetos hábiles en la escritura, pero ocupando lugares diversos en la estructura de gobierno provincial.

Partiendo de las características que debían tener los sujetos para el desempeño de los cargos y las transformaciones que manifiesta la Orden a lo largo de su existencia, es necesario recalcar que durante el siglo XVIII se modifican los objetivos iniciales del siglo XVI. En los orígenes, la Compañía no asignaba un lugar central a la actividad intelectual porque esta no era constitutiva de la identidad jesuita, ya que el misionero ideal era aquel que estaba asociado a la idea de movilidad con la cual la institución se representaba en sus comienzos. Sin embargo, avanzado el siglo XVII y durante el XVIII esta idea fue transformándose al establecerse en colegios y en reducciones por lo cual se sedentarizaba, asumiendo un compromiso con la enseñanza cambiando así el ideal de jesuita (Romano, 2007).

En esta comparación es necesario establecer también los diferentes tipos de escritura que podemos determinar dentro de cada uno de los conjuntos analizados. En este sentido podemos dividir las obras históricas de Lozano en tres grupos la Historia de la Compañia, que obedece directamente a las necesidades de la orden y a la tarea asignada. Esta, al igual que otras historias de la Compañía, refiere a las tareas específicas de los jesuitas en cuanto a su labor de misión en un territorio particular, ya sean particulares o generales. Un segundo grupo lo forman la Historia de las Revoluciones o la Historia de la conquista, que son las que quedan inéditas: se conforman con relatos de sucesos puntuales, en el primer caso, y en el segundo en una historia "descubridora" donde Lozano se explaya al hablar del descubrimiento y la conquista de las tierras luego "regadas" por los jesuitas. Para el historiador era necesario mostrar esos territorios, para luego hablar de los jesuitas, remarcando el buen nombre de la Compañía. Pero, probablemente, no 
respondía a los intereses de la Orden por lo cual quedaron inéditas. El último caso, la Descripción del Chaco, representa otra manera de explicar el mundo como lo era la corografía de la época, presentando un interés específico en el terreno y en la descripción de los pueblos indígenas a los cuales les dedica numerosas páginas. Por su nivel de detalle, y la calidad de las descripciones que hace, es que esta obra - junto a otras del exilio- son consideradas proto-etnografías. La Descripción acompaña la aparición de los vocabularios de las lenguas de grupos indígenas chaqueños lo que marca otra utilidad poniendo de manifiesto la necesidad de misioneros jesuitas, como recurso humano, así como los recursos materiales necesarios para evangelizar la región chaqueña.

De igual forma, podemos establecer diferentes tipos de consulta de acuerdo a la propia especificación del registro, que podían alternar como "consulta de mes", "consulta de operarios", "juntas" — solo en los pueblos de indios— "consulta de maestros", "consulta al tiempo de la visita", "consulta de universidad" y las más numerosas "consulta sobre lo espiritual y lo temporal”, que varían según el tema que se tratara. Como señalamos, dependiendo del tipo de consulta, se incorporaba a la misma algún especialista en el tema, como por ejemplo el rector de la casa, el maestro de novicios, o el procurador de la provincia. Sabemos que estos últimos podían sumarse a la consulta, ya que aparecen mencionados con el cargo que ocupaban, pero no por el nombre. En algunos casos figuran participando de la consulta los consultores ad graviora o de causas mayores que se incorporaban especialmente, aunque no siempre, para tratar temas de obediencia, delaciones y dimisiones.

\section{Las Historias y el Libro de consultas, sus discursos y escrituras}

La primera página del Libro de consultas presenta, como señalamos, un extracto de la carta del General, en la que establecen algunas pautas del procedimiento que debía realizarse indicando que se debía tomar nota, y posteriormente, el secretario de la provincia debía asentar en el libro los temas, las opiniones vertidas y la resolución a la que llegaba el provincial. Es importante señalar que, de acuerdo a las reglas establecidas en el Institutum Societatis Iesu (1893), el provincial estaba obligado a realizar la consulta $\mathrm{y}$, si bien podía tomar algunas decisiones en forma individual, otras debían ser tomadas en conjunto con los consultores, especialmente en algunas causas graves. Algunas cartas de generales refieren específicamente que la decisión debía ser colegiada, aunque no definía cuando una causa podía ser considerada grave. De acuerdo al mismo Instituto, en las reglas del provincial consta la necesidad de llevar un "libelum memorialis" que aparece como una de las tareas que debía realizar el "socci provincilis".

De la misma manera, estas instrucciones establecían que, posteriormente al registro de la consulta, debían realizarse los capítulos, típicos en la escritura jesuítica, que permitían una lectura rápida de manera asequible y mediante los cuales se facilitaba la búsqueda de temas tratados cuando se necesitara para la toma de decisiones. Estos se repiten en todos los folios, resumiendo los temas tratados en la consulta con un gran poder de síntesis en el margen del texto: 
"5 de Octubre estando en el Pueblo de Loreto huvo Consulta con los PPs del Pueblo, y Pe Secretario; y en ella propuso su Ra el Padre Provincial, como el Sor obispo del Paraguay, que al presente se hallava en las Doctrinas le escrivia y le pedia su parecer acerca de si convendria que su Sa Illma se restituyesse a la Asumpcion á causa de los nuevos alvorotos de aquella Ciudad, y en que parece necessitaban, en especial los Ecclesiasticos de su presencia? Todos PP CC juzgaron que convenia dicha vuelta del Sor Obispo à aquella Ciudad" [Escrito al margen: Parecer que pidio El Sor Obispo del Paraguay ${ }^{17}$.

En cuanto al inicio de las historias de Lozano, todas se piensan como un libro y por lo tanto cumplen las formalidades de todo libro del siglo XVIII. Las obras impresas presentan las censuras y permisos obligatorios de la época, pero lo más interesante son los proemios a través de los cuales Lozano se inserta en un marco que los historiadores señalan claramente cuando manifiestan que la escritura de la historia es una tarea hecha por encargo, y a la que responden desde la obediencia, justificando muchas veces su incapacidad para realizarla:

"Habiendo de emprender por impulso de la obediencia el noble asunto de dar al público la historia de la Compañía de Jesús de esta Provincia del Paraguay" (Lozano, 2010, p. 45)

"Esta [la tarea de escribir la historia de la Compañía] por fin se me encomendó a mi, con harto rubor y repugnancia mía, por conocerme destituido de las prendas necesarias, para satisfacer a lo que requiere esta empresa $[\ldots]$ me fue forzoso obedecer"(Lozano, 1754, p. 3).

Si bien el Libro de consultas se muestra como un cuerpo orgánico, pueden observarse cambios de mano en el registro que, a su vez, no coinciden con el cambio de Provincial. Esto es interesante porque implica cuestiones relativas a la administración -y a la formación- de los cuerpos del gobierno de las provincias en la Compañía. Si bien dejaremos abiertos estos interrogantes, para nuevas investigaciones, no podemos evitar señalar que el cambio de la persona que registra las consultas implica, al mismo tiempo, que los asientos puedan ser diferentes y, por esto, nos interesa el cambio de manos. El Libro está escrito en su mayor parte en tercera persona, aunque hemos podido reconocer algunas intervenciones en primera, donde quien escribe aparece en el relato registrando su participación y las opiniones que vertió en la consulta. Estas intervenciones podrían corresponder al "socii provincialis" de Jaime de Aguilar, aunque no podemos afirmarlo todavía por algunas disparidades en la documentación confrontada.

${ }^{17}$ AGN. Sala VII. FBN Nº 62, LdC Folio 001v. 
Los años registrados en el Libro corresponden a los últimos dos años del provincialato de Jerónimo de $\operatorname{Herrán}^{18}$, y los de Jaime de Aguilar, Antonio Machoni y Bernardo Nusdorffer; así como los periodos en que en forma interina - cumplido el plazo de un provincial y hasta que llegara el nuevo pliego de gobierno- asumieron los provinciales Sebastián de San Martin y Pedro de Arroyo. En el Libro se registra el procedimiento de descubrimiento del pliego de nombramiento del provincial entrante, enviado por el General desde Roma, así como los procedimientos que se llevaban a cabo en caso de que dicho pliego no llegara para realizar el cambio de gobierno y la publicación del nuevo provincialato. Nada de este procedimiento aparece en las Historias analizadas, aunque debemos remarcar que ninguno de estos provincialatos es abordado directamente en ellas, salvo alguna mención al cambio de provincial en la Historia de las revoluciones.

La temática tratada en las consultas es muy vasta y podrían establecerse muchas categorías sobre el registro de las vicisitudes de la provincia, dependiendo del análisis que se pretenda realizar o de los objetivos que orienten dicha búsqueda. Si bien nosotros pretendemos concentrarnos en la forma discursiva, y no en el contenido, es necesario señalar que se pueden observar consultas de tipo "espiritual" y "temporal", aunque estas temáticas se tratan indistintamente y en forma conjunta o separada. Por estos motivos no podemos diferenciarlas en forma absoluta a partir del propio relato, ya que en la misma consulta se abordan varios temas. Sin duda, los sucesos humanos no pueden analizarse como compartimentos estancos, por lo cual, como en la vida cotidiana, los hechos se "mezclan". Esto es lo interesante de este registro, que nos permite acercarnos a lo cotidiano de las decisiones del provincial, a modo de una ventana abierta para el historiador. El problema de esta mirada son los términos de "verdad" que manejamos, ya que ni la consulta es una "verdad" ni el relato del historiador una "ficción". En cambio, lo que intentamos entender, con andamiajes teóricos como el que proponemos, es que ni uno es un reflejo verídico ni el otro una construcción apologética, sino que ambos son construcciones retóricas de un sujeto que observa y registra una realidad, cargado de numerosos condicionantes.

Las consultas más numerosas se refieren a lo temporal y comprenden cuestiones relativas a la venta de mulas o la construcción de almacenes, disposiciones netamente prácticas. Asimismo, dentro de estas consultas de tipo temporal, se discutían cuestiones relativas a la obediencia de los sujetos en los traslados, denuncias contra los padres, delaciones de "indios y negros", entre otros. Dentro del mismo tipo se encuentran otras, referidas a los problemas que los jesuitas tenían con "los de afuera" de la Orden, como gobernadores, obispos u otros regulares. En este sentido, abundan las cuestiones relativas al conflicto en la ciudad de Asunción con los comuneros y la expulsión de los jesuitas del colegio de esa ciudad, estableciendo en la consulta las condiciones que pondrían para volver a la ciudad. Sobre este tema hacían especial hincapié en las habladurías que existían contra los jesuitas esperando "que se declare por auto haber sido atentado y sacrílego todo

${ }_{18}$ Jerónimo de Herrán fue provincial de la provincia del Paraguay, desde 1729 a 1733, pero recordemos que el libro comienza en 1731, por lo cual registra solo los dos últimos años de su gobierno. 
Cargnel. Escrituras en la Compañía de Jesús, el libro de consultas de provincia y las historias de provincia.

lo que contra la Compañía y sus individuos se ha obrado y actuado"'19. Sin embargo, no era un tema prioritario si se analiza el conjunto de las consultas, sino que es tratado como uno entre muchas situaciones conflictivas que vivía la provincia. Por otra parte, se señalan las consultas de tipo espiritual como la realización de ejercicios espirituales, disposiciones para los ministerios o las misiones - urbanas o rurales- que se realizaban.

En este análisis realizamos un primer acercamiento a algunas particularidades del Libro, que nos llevaron a indagar sobre el registro de la realidad que estos consultores observaban; pensándolo comparativamente con el registro que se fija en las historias de Lozano, y que necesitarán un tratamiento más intensivo con el avance de nuestros estudios. En primer lugar, nos preguntamos por la necesidad del registro en sí mismo de los acontecimientos y, asociado a esto, la manera en que este proceso se llevaba a cabo. No hay un tratamiento igualitario entre los temas, podemos ver que en algunos se relata con excesivo detalle el acontecimiento y en otras se resumen las temáticas de la consulta. Esto último nos lleva a pensar que en la mentalidad del grupo hay cosas que no deben aclararse, porque se suponen y están insertas en el ambiente en el que se desarrolla la consulta. Por eso debemos tener presente que los jesuitas, como parte de una orden religiosa, tenían elementos compartidos dentro de un sentido familiar que se profundiza en el entenderse como parte de una familia:

"Juzgaron todos los PP, que se debian usar todos los medios, aunque se passasse a los fuertes, para desterrar del Colegio esta peste [hablar con demasiada libertad]; y que assi Su Ra juntasse à todos los PP, y que les avissase con toda eficacia se dexassen de enrredos con seculares, y que de no aver emmienda para en adelante, passaria $\mathrm{Su} \mathrm{R}^{\mathrm{a}}$ a castigar semejante falta con todo el rigor posible de externos" 20

Esta escritura, que refiere al sentido de un cuerpo unido, se manifiesta en algunas decisiones que la provincia tomaba y que llegan a nosotros a través del registro del socio o del historiador. Así, el "nosotros", como una familia que comparte códigos y saberes intra-institucionales, se refleja fuertemente en la escritura. Sobre los gastos de Lozano en su trabajo de historiador, por ejemplo, la consulta señala: "que todos los gastos que se hiciesen así en el padre Lozano como en los hermanos se prorrateasen y dividiesen entre los colegios y misiones del Paraguay y Chiquitos pues era en su pro y no del oficio de provincia"21. La designación de Lozano como historiador provincial, y el prorrateo de sus gastos entre todos los colegios, nos muestra la necesidad que la provincia tenía de una historia que reflejara un pasado aceptado por el presente, en beneficio de todos, sin la necesidad de hacer explícita dicha necesidad.

También podemos observar cuestiones relativas al sigilo que requerían algunos temas en el siglo XVIII, como al referirse a las delaciones, por ejemplo, se argumenta

\footnotetext{
${ }^{19}$ AGN, Sala VII, FBN No 62, LdC folio $40 \mathrm{v}$.

${ }^{20}$ AGN, Sala VII, FBN No 62 , LdC folio $5 \mathrm{v}$.

${ }^{21}$ AGN, Sala VII, FBN No 62, LdC folio 60.
} 
en mayor medida y se tiene especial cuidado en el nombramiento de los implicados al tratar el suceso:

“¿Y pregunto su Reverencia que se haria en fuerza de esto, y de lo demas, que en otras ocasiones se avia visto? Sin manifestar; quien era el nuevo delator, aunque los $\mathrm{CC}$ hizieron harto por sacarlo en limpio. Dos CC dixeron que se despidiera al P. Los otros quatro dixeron, que por las cosas passadas, no se hiziesse, ni se dixesse cosa alguna, por el justo rezelo de fundarse todo en una falta del Sigilo Sacramental; mas que de lo nuevo se le podia hacer cargos al P., si el Delator era sugeto de quien no se pudiesse sospechar falsedad, y añadió uno, que avia fundamento para temerla; assi por no aver avisado en tanto tiempo al Superior inmediato, ni al mediato; como porque el Superior que fue del P. quando sucedió lo que se refiere, se haze lenguas de dicho Padre; y lo mismo hace el Superior que aora tiene; y assi mismo todos los PP. de dicho Colegio, hablan bien de dicho Padre, como lo oyo dicho Consultor. Resolviò pues su Reverencia que no se hablasse nada de lo primero, y se le hiziesse cargos de lo que nuevamente se delatava"22.

Cuestiones de esta índole no tienen lugar en las Historias de Lozano, ya que claramente el objetivo que reflejan sus obras era mostrar otra Compañía: monolítica, generadora de ejemplos y provechosa para las nuevas regiones descubiertas donde los jesuitas misionaban. En este sentido, hemos demostrado que Lozano refleja el cumplimiento de las instrucciones de Aquaviva en cuanto a los lineamientos de escritura abordando "virtudes y acciones especiales de aquellos que murieron dentro de la Compañia", la "santidad de vida, muerte preclara", las vocaciones y conversiones, así como las calamidades que sufrían aquellos que abandonaban la Compañía (Cargnel, 2015). En el relato no hay términos medios para hablar de las acciones de los jesuitas, no aparecen las discusiones ni la necesidad de "llamar la atención" a los padres que aparecen en el otro registro.

La cita anterior también nos permite observar el registro de un relato oral que, al transformarse en formato escrito necesita dejar un asiento cuasi literal de la discusión en la consulta. Así podemos ver, frases como "pregunto su reverencia que haría de esto”, “añadió uno”, en las cuales el lenguaje oral se cuela y se hace visible a nosotros a través del documento, remarcando la necesidad de asentar la argumentación de cada consulta. En este sentido, se puede observar un registro del conflicto, visibilizado a través de las opiniones diferentes que se emiten, pero que se cierra sobre sí mismo sin permitirnos mayores accesos. Estas expresiones nos llevan a pensar que este es el registro directo de la consulta y no las notas tomadas y transcriptas.

"A esto ultimo todos respondieron, que por aora no se le

${ }^{22}$ AGN, Sala VII, FBN Nº 62, LdC 59. 
Cargnel. Escrituras en la Compañía de Jesús, el libro de consultas de provincia y las historias de provincia.

obligasse à estudiar, ni examinarse, y que interrumpa, y despues si se hallare para ello se examine, y si fuere aprobado, prosiga sus estudios" ${ }^{\prime 23}$.

"Item si seria conveniente suspender, y detener al P. Sebastian de San Martin Superior de Chiquitos por no saber su lengua" ${ }^{24}$. "Item si seria conveniente suspender, y detener al P. Sebastian de San Martin Superior de Chiquitos por no saber su lengua, y porque en iendose los Pro...es a Roma es factible que quede hueco que el Padre puede llenar"25.

Podemos señalar, también, que, en líneas generales, no aparecen los nombres de los sujetos. Aunque no podemos afirmar las razones para ello, ya que hay un tratamiento heterogéneo en este sentido, creemos que las motivaciones más fuertes serían las que tienen relación con el cuidado de prestigio de las personas. Por esto, aparecen los sujetos mencionados con los nombres tachados, las iniciales, solo el nombre y la inicial del apellido y otras combinaciones, aunque en algunas oportunidades también aparecen los nombres completos, por lo cual es difícil establecer patrones todavía. Es importante remarcar que la consulta debe entenderse como una praxis enmarcada en una retórica, que funciona inconscientemente entre los individuos, más allá de la obediencia para la escritura, por la estructura de pensamiento de la época. En este sentido, la comunicación se plantea como un reflejo de lo sucedido, pero que al pasar de la oralidad a la escritura aparece otro producto marcado por la autocensura y el disciplinamiento propios del siglo XVIII: "el día 6 de agosto hubo consulta en que se trato sobre la profesión del P. N. Que ya había cumplido y se reparo en la libertad que tenia dicho padre de hablar en el pulpito contra los eclesiásticos y de lo mucho que se detenía en el confesionario y eso después de haberle reprehendido"26.

Sin dudas la época señala diferencias entre el registro oral y el escrito, pero nos interesan los condicionantes que llevaban a cuidar, en el asiento de esas discusiones, los términos que se utilizaban aún en el registro de un documento que suponemos tenía grandes niveles de secreto y de intimidad, ya que era el órgano de consulta y de decisión del provincial. No podemos dejar de señalar que, si en estos niveles de secreto se cuidan estos detalles, debemos entenderlos como propio de la época y no de la situación de la consulta, ya que en la Orden, como en toda familia, todos se conocen entre sí. Asimismo, no hacer mención directa a otros jesuitas es parte de no ofender, pero especialmente de evitar que algunas informaciones cayeran en manos no amigas. Por otra parte, son cuestiones que, como señalamos más arriba, no aparecen en el otro corpus que manejamos, ya que el jesuita construido para la historiografía es solo virtuoso.

Mucho podría decirse de la consulta en cuanto al cuidado del buen nombre de los sujetos y, también, del buen nombre de la Compañía como institución. En esto se

${ }^{23}$ AGN, Sala VII, FBN N ${ }^{\circ}$ 62, LdC 103.

24 AGN, Sala VII, FBN No 62, LdC 32.

25 AGN, Sala VII, FBN No 62, LdC 32.

${ }^{26}$ AGN, Sala VII, FBN N ${ }^{\circ}$ 62, LdC 54. 
pueden conjugar la necesidad de expresar la forma en que se cuidaba la reputación y, al mismo tiempo dar por supuesto, en ese universo de significaciones compartidas, lo que se entendía por la honra de una persona o de una institución en el contexto conflictivo de la primera mitad del siglo XVIII: "En 29 de Setiembre ubo consulta en preguntó su Reverencia el P. Provincial si seria conveniente conservar la Mission de los Lules? Todos fueron de parecer, que se conservase, sin desistirnos de ella, por nuestro buen nombre"27.

Otro aspecto que refleja la oralidad del texto podemos encontrarlo en la presencia de fórmulas que se repiten, aunque no literalmente. Si partimos del preconcepto de la Orden regulada y monolítica, pensaríamos que el Libro también reflejaría un asentamiento del registro estructurado. Sin embargo, hay una gran disparidad a la hora de la consulta que nos muestra la espontaneidad y la conflictividad vivida en la provincia. En este sentido, hay algunas fórmulas que se pueden encontrar, por ejemplo en la lectura de las reglas de los consultores, en los casos en que solo se registra que se leía el memorial y se asentaba lo dispuesto, especialmente en las visitas que hacía el provincial a los colegios, a las estancias o a las doctrinas: "en Santa Catalina y en Candelaria hubo consulta dicho mes y se determinó lo que queda en el memorial de una y otra estancia" 28 o "En la consulta de Operarios se determino lo que queda en el Memorial"29.

Aún más claramente pueden observarse en aquellas frases que tienen que ver con el final de la consulta: "Preguntò mas su Reverencia: si se avia notado algo en la Provincia, que pidiesse remedio? Todos dixeron que no" 30 . "Pregunto mas su Reverencia si avia alguna cosa en la Provincia, digna de remedio? Nada se ofreció" 31 .

\section{Consideraciones finales}

Partiendo de las nociones propuestas por Luhman (2006) que guiaron este trabajo, realizamos un tipo de observación sobre "el Libro de consultas", que propone prestar mayor atención al libro en sí mismo sin priorizar el mensaje que transmite del pasado. A partir de la comparación con una forma discursiva más estudiada, como lo es la historiografía jesuita, buscamos entender este documento como una "forma" distinta de registro escrito de la realidad que observaba "un" jesuita quien, a su vez, ocupaba un lugar determinado en la estructura de la Orden.

Podemos afirmar que las necesidades de ese presente, y de la forma de gobierno, condicionaban a quien tomaba registro de las discusiones del provincial reunido en consulta con su grupo de consultores. Nuestra preocupación central es comprender las diferencias de las formas de escritura en un mismo contexto, ya sean registradas por el socio o por el historiador de la provincia jesuítica del Paraguay en la primera mitad del siglo XVIII. Por esto nos interesan los condicionamientos del escribiente, que se filtran

\footnotetext{
${ }^{27}$ AGN, Sala VII, FBN No 62, LdC $27 \mathrm{v}$.

28 AGN, Sala VII, FBN No 62, LdC 25.

${ }^{29}$ AGN, Sala VII, FBN N ${ }^{\circ} 62$, LdC 27v.

${ }^{30}$ AGN, Sala VII, FBN No 62, LdC 34v.

${ }^{31}$ AGN, Sala VII, FBN N 62, LdC 86.
} 
Cargnel. Escrituras en la Compañía de Jesús, el libro de consultas de provincia y las historias de provincia.

a través de la escritura y que nos acercan al presente en el que vivían, más allá de las razones que llevaban al acto de consulta del provincial y las resoluciones que tomaban.

En estas páginas, comparamos una forma de registro de los discursos del siglo XVIII en la antigua Provincia Jesuítica del Paraguay, a través del Libro de consultas, con otra forma representada por las Historias de Lozano, que nos ofrecen la historia que la Compañía pretendía brindar de sí misma. Entendemos que solo podremos acercarnos a narraciones sobre los sucesos, siguiendo también a Ricoeur (2004) quien distingue el hecho histórico del acontecimiento, ya que entiende que el primero es un constructo lingüístico, por eso es plausible de ser verdadero o falso, mientras que el segundo es el suceso en sí, aquello que ocurrió a lo que no podemos acceder. Es por esto que consideramos válido el acercamiento a un momento histórico de la Compañía desde la construcción de los distintos textos y no al suceso propiamente dicho, pudiendo observar en estos registros, "dos" Compañías, una cotidiana y problemática que difiere de la monolítica y disciplinada mostrada por la historiografía construida a su alrededor.

El Libro no muestra una construcción de las "virtudes y proezas" de los jesuitas, ni un relato orgánico y lineal como las "Historias", sino que es el asiento de los problemas administrativos y los conflictos que debía resolver el Provincial continuamente. Sin embargo, por ser ambos parte del mismo sistema, se pueden observar puntos de contacto en el registro, pero con funciones claramente diferenciadas. Asimismo, consideramos que no podemos leer el Libro de consultas como una expresión de los hechos de ese pasado inasible, aunque nos permite realizar una mirada más cotidiana de los sucesos que la fijada en las historias oficiales. Por esto, ningún texto puede entenderse como reflejo de la "verdad" sucedida, entendiendo la escritura de la Historia como Certeau (1993), quien plantea la necesidad de tener presente que el historiador no hace la historia, sino que hace una Historia; la cual estará cerca del poder del cual recibe directivas y que toma posiciones que, a su vez, no siempre son las del historiador sino las de la institución a la que pertenece.

El Libro de consultas, por ser un documento administrativo de la Compañía que no estaba destinado a mostrarse y por la cotidianeidad del registro que refleja, fue entendido como un documento que manifestaba el pasado tal cual sucedió, como parte de una propuesta historiográfica superada. Nosotros proponemos otro tipo de análisis, restando atención al contenido, en tanto mensaje, para prestar atención al registro en sí mismo. La regulación de la Compañía nos permitía pensar que dicha consulta obedecería a reglas sistémicas por las que informaban de determinada manera, y desde allí establecer relaciones entre la escritura del cronista y el Libro de consultas. No pretendemos plantear esta relación en términos de verdadero o falso, sino como una relación proporcional de niveles de conflictividad de tipo administrativo, funcional y disciplinar que se reflejan en ambos escritos. Enfrentados estos últimos con hechos históricos que nos remiten al pasado glorioso y sin desacuerdos en el mismo espacio. En este sentido, la redacción de Lozano nos remonta a momentos de orden y de calma, que debemos entender como un reflejo de una situación que se pretende mostrar inversamente proporcional al registro de conflictividad que emerge en el otro documento analizado. 
Dejando de lado el papel del historiador como buscador de "la verdad" de los hechos del pasado, nos propusimos comprender la problematicidad del Libro desde la inteligibilidad, intentando entender su funcionamiento como registro de la realidad que vivía quien lo escribió, en tanto parte de un sistema, ya que como señala Luhman (2006) no hay realidad sino aquella que es observada. Desde este lugar pensamos que los escritos jesuitas deben verse como una realidad construida y socialmente compartida, que intenta transformarse en una verdad que pretende convertirse en absoluta para mostrar una imagen de la Compañía, frente a otra que pretende desvirtuarla o, incluso, frente a su propio presente. Certeau (1993) afirma que no se puede borrar la particularidad del lugar desde donde habla el historiador y el ámbito desde donde investiga; en este sentido, es claro que son dos tipos de registros heterogéneos, realizados con diferentes objetivos y por distintas personas, ya que mientras uno refleja el presente el otro se ocupa del pasado, pero que se cruzan por ser escritos en forma simultánea.

A través de estos textos se hace presente la idea de una realidad que puede ser observada de distintas maneras, pero que la Compañía pretende unificar en su discurso porque prevalece el objetivo principal de la institución que es la gloria de Dios. Es ese mismo presente en "desorden" el que los lleva a escribir sobre un pasado en el que prima la calma y en el que la Orden se destaca, evangelizando indígenas o haciendo misiones que rescatan a la población de la "condena eterna" entendida en la época como la vida fuera de la religión católica. Así, el reflejo pone distancia, porque esa historiografía escrita por el historiador en la primera mitad del siglo XVIII muestra una participación gloriosa y monumental, que corresponde a un sentimiento de debilidad del cuerpo y a las grietas que podemos observar en el libro de consulta.

Este análisis pretende observar la escritura entendiendo que lo que cuenta del pasado no es el pasado, sino una narración de algo que ha sido, pero ya no es. En el mismo toda esta documentación nos brinda niveles argumentales complejos para entender dicha realidad desde una multidimensionalidad. El Libro presenta numerosos conflictos de interpretación: la particularidad del documento, la falta de uniformidad y sus secuencias descompasadas — tanto en el registro como en la temática一, la presencia de la primera persona en un texto narrado mayormente en tercera. A estos se suman la carta inicial y sus errores que nos remiten a la originalidad del documento; así como los aspectos relativos al momento de la escritura: si se toman notas para una reescritura más elaborada o si se escribe al momento mismo de la consulta. Las Historias de Lozano, en cambio, nos muestran relatos orgánicos, que suman transcripciones de documentos y consulta de otras obras para dar sostén a un discurso que se realiza por obediencia y que no pierde el sentido apologético y funcional a la Orden.

Sin dudas, de todos estos aspectos solo podemos pensar en muchas preguntas que quizás encuentren sus respuestas en el paso del tiempo y en el trabajo profundo. Lo que nos permita reconstruir las prácticas del registro, y la forma en que se llevaba a cabo, para así acercarnos a las observaciones de las construcciones que los consultores -y quien registraba esas discusiones- hacían del presente que observaban. En este sentido, creemos que el camino es pensar en la escritura entendiendo que se convierte 
Cargnel. Escrituras en la Compañía de Jesús, el libro de consultas de provincia y las historias de provincia.

en una característica del "ser" jesuita del XVIII. Ya sea historiador o consultor, todos los jesuitas se enfrentan a la escritura, y cada uno desde el lugar que ocupaba nos dejará una visión, y son estas visiones reflejadas en formas diferentes las que el historiador deberá tener en cuenta en el momento de tejer su narración, ya que una forma comunica diversamente a otra.

\section{Fuentes}

Archivum Romanun Societatis Iesu (ARSI), Fondo Paraquaria. Catálogus Publicus Provinciae Paraquaria.

Archivo General de la Nación, Sala VII, Fondo Biblioteca Nacional Nº 62, LdC 54.

\section{Referencias Bibliográficas}

Alcantara Bojorge, D. (2009), "El proyecto historiográfico de Claudio Acquaviva y la construcción de la Historia de la Compañía de Jesús en la Nueva España a principios del siglo XVII". Estudios de Historia Novohispana $\mathrm{N}^{\circ} 40$, enero-junio 2009, Instituto de Investigaciones Históricas-UNAM: México, pp. 57-80.

Cargnel, J. (2015). La historiografía de la Compañía de Jesús. Pedro Lozano, su historiador, Tesis de Doctorado, Córdoba, FFyH-UNC, Inédita.

Certeau, M. (1993). La escritura de la Historia. México: Iberoamericana.

Chartier, R. (2001). Escribir las prácticas. Foucault, de Certeau, Marín. Bs. As.: Manantial. Furlong, G. (1959). Pedro Lozano y sus Observaciones a Vargas. Bs As: Librería del Plata. Galhegos Felipe, G. y Paz, C. (2019). "Intersecao de subjetividades: a presenca indígena na escrita afetada dos jesuitas". Historia da historiografia 12, N 30, pp. 198-232.

Institutm Societatos Iesu Volumne tertium. Reguale, Ratio Studiorum, ordinationes, instructionis, industriae, excercita, directorium. (1893) A SS Conceptione: Florentiae ex typographia.

Lozano, P. (1941). Descripción Corográfica del Gran Chaco Gualamba. Radamés A. ALTIERI (ed.) Tucumán: Universidad Nacional de Tucumán.

Lozano, P. (2010). Historia de la conquista del Paraguay, Río de la Plata y Tucumán. Estudio preliminar y edición de Ernesto Maeder. Bs As: Academia Nacional de la Historia.

Lozano, P. (1754). Historia de la Compañía de Jesús en el Paraguay. Madrid: Imprenta de la viuda de Manuel Fernández.

Lozano, P. (1905). Historia de las revoluciones del Paraguay, 1721-1735. Enrique PEÑA y Samuel LAFONE QUEVEDO (eds.), Bs. As.: Cabaut.

Luhman, N. (2006). La sociedad de la sociedad. México: Iberoamericana.

Morales, M. (2005). A mis manos han llegado. Cartas de Padres Generales a la antigua provincia del Paraguay (1608-1639): Madrid/ Roma, Comillas/Institum Historicum Societatis Iesu.

O’Neill, C. y Domínguez, J. (2001). Diccionario Histórico de la Compañía de Jesús. Madrid: Universidad Pontificia Comillas.

Ricoeur, P. (2004). La memoria, la Historia y el olvido. México: Fondo de Cultura Económica. 
Romano,A. (2007). “Actividad científica y Nuevo Mundo: el papel de los jesuitas en el desarrollo de la modernidad en Iberoamérica". En: Los jesuitas y la modernidad en Iberoamérica. 1549-1773. (pp. 56-71). Lima: Fondo Editorial de la Universidad del Pacífico.

Salinas, M. y otros. (2017). Cartas Anuas de la Provincia Jesuítica del Paraguay. 1714-1720. 1720-1730. 1730-1735. 1735-1743. 1750-1756. 1756-1762. Asunción: CEADUC. 